\title{
Pérez Álvarez, M. (2021). Ciencia y pseudociencia en psicología y psiquiatría. Alianza Editorial. 488 páginas.
}

Juan Carlos Fernández Castrillo

Colegio Oficial de la Psicología de Madrid

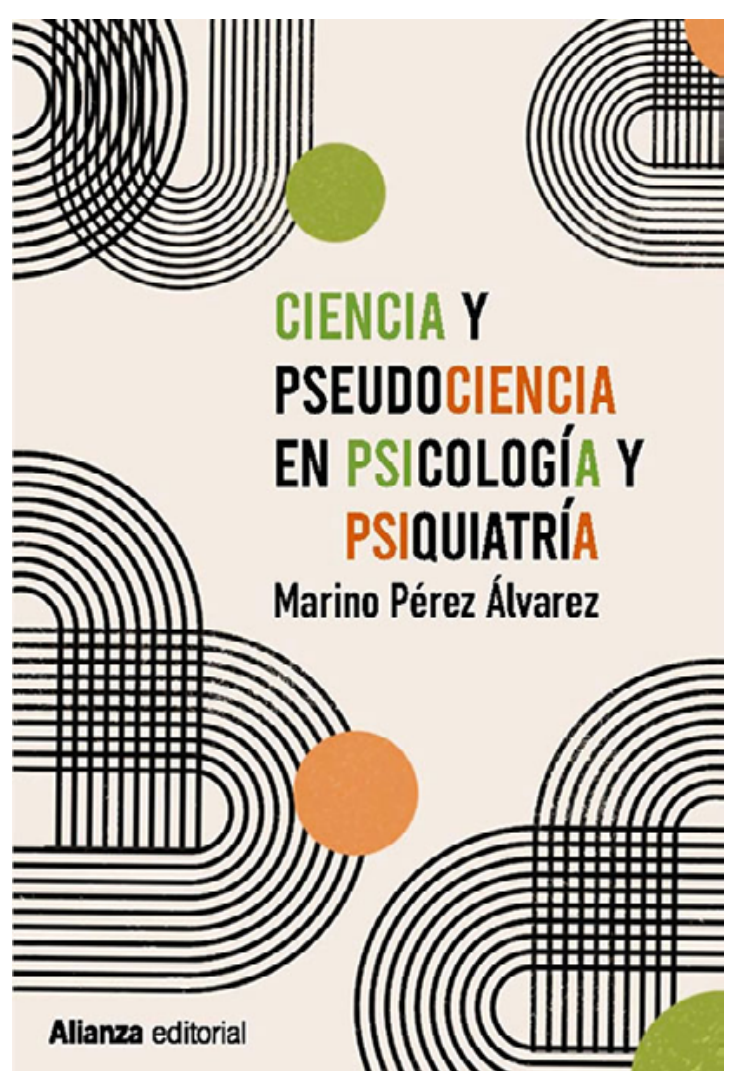

Algunos libros te pueden cambiar la vida. "Puede que la vida de un lector se divida en dos: antes y después de haber leído La Montaña Mágica”, decía el premio Nobel de Literatura en 2010, muy polémico en otros ámbitos, Vargas Llosa, al referirse a la novela de Thomas Mann, texto que acabo de releer; estaré, por tanto, si se produce el efecto comentado, en el segundo antes y después en mi vida. Ahora voy a aplicar esta observación y pronóstico a aquellos de los y las colegas que hagan honor literal a esta idea y se sumerjan en el libro que nos ocupa, porque puede que su manera de entender la psicología como ciencia en el cruce de fronteras de las ciencias naturales, humanas y las humanidades, como se menciona en una de las contrasolapillas del libro (lo he leído en papel, pero también está disponible en $e$-book), les cambie su modo de entender al menos nuestra profesión.

Marino Pérez Álvarez es catedrático en el Departamento de Psicología de la Personalidad, Evaluación y Tratamientos Psicológicos de la Universidad de Oviedo, un autor con numerosos artículos y libros publicados, de los que me interesa destacar La invención de trastornos mentales, coescrito con Héctor González Pardo, con un subtítulo también estimulante: “¿Escuchando al fármaco o al paciente?", que sembró una rica polémica en 2007.

He recordado, con sumo gusto también, la polémica que Marino Pérez Álvarez mantuvo con el también catedrático de Psicopatología en la Facultad de Psicología de la Universidad Complutense de Madrid, Carmelo Vázquez, a propósito de la psicología positiva, uno de los últimos movimientos que se ha introducido en la psicología del siglo XXI, como aportación o como división, conceptualizado como un avance o la "tiranía del positivismo" carente del rigor científico suficiente, ecos de la cual también encontraremos en el libro reseñado aquí.

Los lectores inquietos pueden ir directamente a la Parte II, que se ocupa de la "Ciencia y pseudociencia: más fácil de mostrar que de demostrar". La bondad y la habilidad de evocación de este título desbroza el campo

(cc) $\mathrm{B} Y-\mathrm{NC}-\mathrm{ND}$ Este es un artículo Open Access bajo la licencia CC BY-NC-ND. 
que en los últimos años se ha llenado de opiniones, informes institucionales nacionales y foráneos (visiten, si no lo conocen ya, la web gubernamental www.coNprueba.es sobre las pseudoterapias y pseudociencias, o los documentos de la comunidad científica del ámbito de la psicología australiana, por ejemplo), críticas y contracríticas que alimentan la divulgación científica, la solvente y la otra también.

Disfrutemos en estos capítulos (4 al 9) con unas clarificadoras argumentaciones sobre el procesamiento por movimientos oculares (EMDR), sin que la terapia cognitivo-conductual (CBT, por sus siglas en inglés) se escape al análisis meticulosamente crítico; y no se pierdan tampoco las esclarecedoras y refrescantes ideas sobre la "psicopalabrería" (autoayuda, coaching, inteligencia emocional o mindfulness) y la "neuropalabrería" (seducción neurocientífica, función ejecutiva y neuronas espejo).

La tercera y última parte del volumen se ocupa de la "Psicoterapia: más allá de la analogía médica". Si me permiten apuntarles una elección personal, aunque es difícil elegir una joya entre un ramillete de ellas, aquí encontramos mi preferencia, sus elocuentes y estimulantes palabras sobre el "Sempiterno efecto placebo: de la medicina a la psicoterapia". Pues si creían tener sólida y robustamente asentada la comprensión sobre qué es y cómo influye el placebo, con su doble origen "negativo" y "positivo" del mismo, lean despaciosamente el capítulo 11, no lo lamentarán.

Pero, atención, si hacen esto, saltar sin pértiga, se perderán la Parte I, que arranca y se adentra en el mejor y más necesario paseo por la filosofía; sencillas, comprensibles reflexiones, aunque no menos rigurosas, componen los primeros capítulos. Sirva de muestra un botón, la propuesta del autor sobre la psicoterapia científico-humana, que bebe y vive de la sophia, la episteme, la téchne, la phronesis y la metis, conocimientos todos ellos inherentes, según Marino Pérez, a la psicoterapia. Cada capítulo concluye con un resumen, lo que ilustra también el buen hacer pedagógico del autor.

El libro concluye con una útil recapitulación para exponer cómo la psicoterapia ha de ser aprehendida, según el autor, si se quiere escapar del pensamiento que la corriente principal (mainstream), como pensamiento dominante, incluso esterilizante y contrario al desarrollo del buen hacer en las intervenciones terapéuticas en estos ámbitos de la clínica de las enfermedades, trastornos y malestares psicológicos y psiquiátricos.

Cierro con otra cita, esta vez de Alberto Caeiro (heterónimo de Fernando Pessoa, el extraordinario poeta luso): "Pensar molesta tanto como andar bajo la lluvia cuando arrecia el viento". Solo para quien esto suscriba, a los reticentes a pensar más cómodos en el dejarse arrastrar por la corriente principal, no recomiendo la lectura reflexiva de este libro de Marino Pérez Álvarez, para los demás, entre los que me encuentro, ya estamos esperando para sumergirnos pronto en su próximo libro. 